\title{
Game Theory Applications in Statistical and Quantitative Techniques
}

\section{Dr.DaruriVenugopal}

Professor, Department of Mathematics, OPJS University, Churu, Rajasthan, India.

\section{To Cite this Article}

Dr.DaruriVenugopal, "Game Theory Applications in Statistical and Quantitative Techniques", International Journal for Modern Trends in Science and Technology, 6(8): 296-302, 2020.

Article Info

Received on 28-July-2020, Revised on 12-August-2020, Accepted on 18-August-2020, Published on 26-August-2020.

\section{ABSTRACT}

Game Theory is Statistical Techniques applied in several Sectors. The man objective of the games theory is to work out the decision options where there are conflicting inputs and competitions indicating the final outcome of the games. It is alternative course of action available to players in game concept. This manuscript explains the different assumptions considered in game theory applications. Provides the concept of Zero-Sum game, Saddle point requirement, Solving the problems without saddle points. Concept of Linear Programming Method is also merged in Game Theory for easy understanding of given Problem. It also Provides the Limitations of Game Theory, Dominance, mixed Strategies and Explains the concept of Solving the Game graphically. It provides the Arithmetic method game solving of, $2 \times 2 ; n X n$ and its extension methods of Payoff matrix.

KEYWORDS: conflicting, decision, dominance,payoff matrix, Saddle point, strategies.

\section{INTRODUCTION}

It is a decision making mathematical method under conflict situation. When the problem is concerned fundamentally with the action of competitors in such situations we use Game Theory applications. The major utilization of the games theory is to work out the decision options where there are confliction inputs and completions indicting the final outcome of the games. In game situation each of the players is required to have a definite set of strategies under rational application of rules set in for the game. Each players a set of contingencies and uses the best under the circumstances, reacting to the strategy used by the opponents.

In many Statistical analysis problems it is mandatory to take decision in a situation where there are two or more opposite parties with conflicting interests and the action of one depends upon the action which the opponent takes. The result of the situation is controlled by the decisions of all the parties involved. Such a decision policy duration is termed as a competitive situation. Such problem occurs frequently in economic military, social, political, advertising and marketing by competing business forms. We can identify that a list of limited or infinite number of possible courses of action is available to each player. In general practice two person games are of more importance and further the extension of $n X n$ matrix form of payoff matrix solving.

\section{ZERO SUM - TWO PERSON GAMES}

If a player known exactly what the other players I going to do, a deterministic situation is obtained and objective function is to maximize the gain. The 
pure strategy is a decision rule always to select a particulars course of action.

Two person with zero sum is also known as rectangular games. In this case the loss or gain of one player is exactly equal to the gain or loss of the other player. We also call the representation form of this rectangular game as pay-off matrix. In simple words if the algebraic sum of gains and losses of all the players in a game is zero then such game is known as zero-sum Game other wise it is called a non zero sum game. The following are the few of the Characteristics of Game Theory Applications.

- The amount of information about the past activities of other player to a player.

- Number of activities which may be limited or infinite.

- Each player has a number of alternative available during a particular play.

\section{MAXIMIN - MINMAX METHOD}

In any payoff matrix we mention minimum of maximum by minimax and maximum of minimum by maximin. In general the selection of strategies by $A$ and $B$ was based upon maximin, minimax principle which guarantees the best options. If Maximin value and minimax values of the game are equal then it is said to be Optimum strategies.

Example-1

Player-B

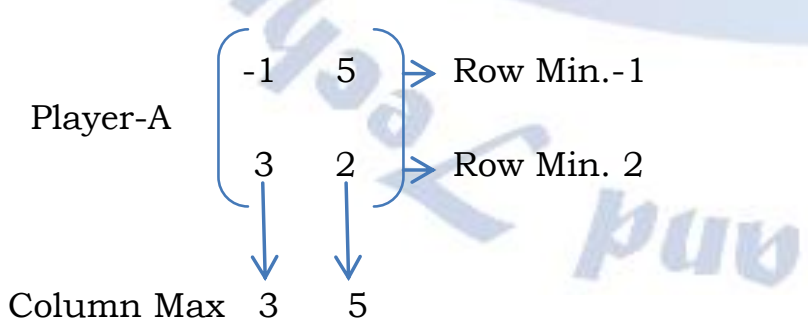

\section{SADDLE POINT VALUE OF THE GAME}

Saddle point is the point where the maximum of row minima coincides with the minimum of the column maxima then the payoff at the saddle point is called the value of the game denoted by ' $\mathrm{v}$ ' in general. When maximin is not equal to minimax then pure strategy fails. Such condition is known as mixed strategy.

\section{Example-2}

Soling the Pay-off Matrix :

Player:B

$\begin{array}{ll}\text { Player: } \mathrm{AA}_{2} & \mathrm{~A}_{1} \\ & 0 \\ \mathrm{~A}_{3}\end{array}\left(\begin{array}{ccc}\mathrm{B}_{1} & \mathrm{~B}_{2} & \mathrm{~B}_{3} \\ 1 & 5 & 1 \\ -6 & -2 & \\ 1 & 5 & -1\end{array}\right)$

Row Min(1,-6,-1) \& Column $\operatorname{Max}(1,5,1)$

$\therefore$ Saddle Point $(1,1)$

$$
S_{0}=\left(A_{1}, B_{1}\right) \text { or }\left(A_{2}, B_{3}\right)
$$

\section{Example-3}

Soling the Pay-off Matrix :

Player:B

$\left.\begin{array}{lllllllll} & & & \\ \text { Player:AA } & \mathrm{A}_{1} & 2 & \mathrm{~B}_{1} & \mathrm{~B}_{2} & \mathrm{~B}_{3} \mathrm{~B}_{4} & \mathrm{~B}_{5} \\ 1 & 4 & 6 & 0 & 8 & \\ & \mathrm{~A}_{3} & 2 & 2 & 7 & & \\ & \mathrm{~A}_{4} & 3 & -1 & & 1 & 2 \\ 5 & -2 & 2 & 2 & 1\end{array}\right)$

Row $\operatorname{Min}(0,2,-1,-2)$

$\therefore$ MAX. of Row MIN $=2$

Column $\operatorname{Max}(5,6,6,2,8)$

$\therefore \quad$ MIN of Col.MAX $=2$

$\therefore$ Saddle Point $\left(\mathrm{A}_{2}, \mathrm{~B}_{4}\right)$

Volume of the Game $(\mathrm{V})=2$

\section{Example-4}

Soling the Pay-off Matrix :

Player:B

\begin{tabular}{|c|c|c|c|c|}
\hline & & $\mathrm{B}_{1}$ & $\mathrm{~B}_{2}$ & $\mathrm{~B}_{3}$ \\
\hline & $\mathrm{A}_{1}$ & -1 & 4 & -2 \\
\hline Player:AA 2 & 3 & 6 & -3 & \\
\hline
\end{tabular}


Row Min. ( -2,-3 ) ; Column Max.(3, 6, -2)

MAX. of Row MIN = -2

MIN.of Column MAX. $=-2$

$\therefore$ Saddle Point: $\left(\mathrm{A}_{1}, \mathrm{~B}_{3}\right)$

Volume of the Game : $\mathrm{V}=-2$

\section{Example-5}

Soling the Pay-off Matrix for ' $\lambda$ '

Player:B

Player:AA $\left.\begin{array}{ccccc} & & \mathrm{A}_{1} & -1 \\ \mathrm{~A}_{3} & \mathrm{~B}_{1} & \mathrm{~B}_{2} & \mathrm{~B}_{3} \\ \lambda & 5 & 2 \\ \lambda & -8 & \\ -2 & 1 & \lambda\end{array}\right)$

Row $\operatorname{Min}(2,-8,-2)$

$\therefore$ MAX. of Row MIN $=2$

Column Max (-1, 5, 2$)$

$\therefore$ MIN of Col. MAX $=-1$

By the determinable condition

Max $\cdot \operatorname{minvalue}=0=$ Min $\cdot \max$ value

$\therefore-1 \leq \lambda \leq 2$.

\section{LINEAR PROGRAMMING METHOD}

To solve the game problem of larger dimensions we use linear programming approach method.

Let $\mathrm{V}$ be the value of the game problem.

Assume that $p_{1}, p_{2}$ are the probabilities of selecting $\mathrm{a}_{1}$ and $\mathrm{a}_{2}$ strategies by $\mathrm{A}$.

Assume that $\mathrm{p}_{1}, \mathrm{p}_{2}$ are the probabilities of selecting $\mathrm{a}_{1}$ and $\mathrm{a}_{2}$ strategies by $\mathrm{B}$.

Then We have

$\mathrm{C}_{11} \mathrm{P}_{1}+\mathrm{C}_{12} \mathrm{P}_{2} \geq \mathrm{V}$ and $\mathrm{C}_{21} \mathrm{P}_{1}+\mathrm{C}_{22} \mathrm{P}_{2} \geq \mathrm{V}$

Where $\mathrm{p}_{1}+\mathrm{p}_{2}=1$ and $\mathrm{p}_{1}, \mathrm{p}_{2} \geq 0$

\section{Game theory Limitations}

- The main and basic presumption in games theory is that loss of one competitor will be the gain of the other. But practically, there is no application of games theory in real life situation, because the strategies of the competitors and their pay-offs are not normally known or can not even be predicted.

- When there is lack of definite information of data, the principle of maximin and minimax cannot be applied. In such type of situations risk will be taken as uncertain outcome.

- In real life situation in general there are more than two competitors and hence balancing of gain and loss is also no always possible. Such type of condition is known as non-zero-sum-games.

- Variables and uncertainties being very large games have an infinite number of pure strategies involved and the solution of the game is more and more complicated.

\section{DOMINANCE RULE}

- Rule-1:If all the values in a row are less than or equal to the corresponding values in another row, then the row is said to be dominated by the remaining row and that can be deleted.

- Rule-2:If all the values of column in a matrix are more or equal to the corresponding elements in another column, then the column is dominated by the other column and can be eliminated from the matrix.

- Rule-3:In general in any problem strategy may be dominated if it is inferior to average of two or more pure strategies. If the average values of two rows or two columns are found dominated as per rule of above conditions then these can be deleted.

\section{Example-6}

Applying Dominance to the given Matrix 
Using Rule-1 Pay-off $\mathrm{A}_{2}$ are less to row $\mathrm{A}_{3}$.

Hence deleting $\mathrm{A}_{2}$ from the Pay-off matrix.

$$
\begin{aligned}
& \mathrm{A}_{1} \\
& \mathrm{~A}_{3}
\end{aligned} \quad\left(\begin{array}{rrr}
9 & 8 & -7 \\
6 & 7 & 7
\end{array}\right)
$$

Using Rule-2 : Pay-off $\mathrm{B}_{2}$ dominating $\mathrm{B}_{3}$. Hence deleting $B_{3}$ from the Pay-off matrix.

Resulting Matrix

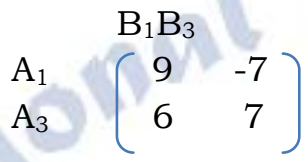

There is no saddle point in this matrix hence need to apply different method of solution.

- Let players A be playing strategy A1 with the probability $\mathrm{p}$ and A2 with probability $(1-\mathrm{p})$.

Solving for $\mathrm{B}_{1} \& \mathrm{~B}_{3}$

- Pay-off matrix for A:

$$
9 p+6(1-p)=3 p+6
$$

- Pay-offatrix for A:

$$
-7 p+7(1-p)=7-14 p
$$

Solving (1) \& (2) for 'p' \&' q'

$$
\mathrm{p}=1 / 17
$$

Similarly $\mathrm{B}_{1}$ as $\mathrm{q}$ and $\mathrm{B}_{3}$ as (1-q)

$$
9 q-7(1-q)=6 q+7(1-q)
$$

$$
q=14 / 17
$$

A will select strategy A1 with probability $1 / 17$ and strategy $A_{3}$ with probability 16/17.

Similarly Player B selects strategy $B_{1}$ with probability 14/17 and B3 with probability 3/17

Substituting the values in any of the expression ....(1) or (2) then we get

$$
\begin{aligned}
& \mathrm{V}=3 \mathrm{p}+6=105 / 17 \quad(\text { or }) \\
& \mathrm{V}=6 \mathrm{q}+7(1-\mathrm{q})=105 / 17
\end{aligned}
$$

$\therefore$ Expected optimal gain of $\mathrm{A}$ and expected optimal loss of

$B=105 / 17$

\section{Example-7}

Solving Pay-off matrix without Saddle point:

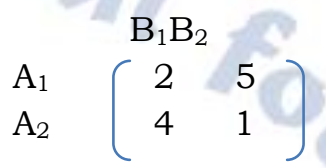

Sol:- Let the Strategies $\mathrm{S}_{\mathrm{A}} \& \mathrm{~S}_{\mathrm{B}}$

$\mathrm{S}_{\mathrm{A}}:\left(\begin{array}{ll}\mathrm{A}_{1} & \mathrm{~A}_{2} \\ \mathrm{p}_{1} & \mathrm{p}_{2}\end{array}\right) ;$

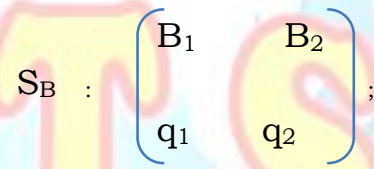

$\lambda=a_{11}+a_{22}-\left(a_{12}+a_{21}\right)=2+1-(5+4)=-6$

$\mathrm{p}_{1}=\left(\mathrm{a}_{22}-\mathrm{a}_{21}\right) / \lambda=(1 / 2)$

$\mathrm{p}_{2}=(1 / 2)$

$\mathrm{q}_{1}=\left(\mathrm{a}_{22}-\mathrm{a}_{12}\right) / \lambda=(1 / 3)$

$\mathrm{q}_{2}=(2 / 3)$

$\mathrm{SB}=$

$\mathrm{B}_{1} \quad \mathrm{~B}_{2}$ $2 / 3 \quad 1 / 3$

Value of the Game: $\left(a_{11} a_{22}-a_{12} a_{21}\right) / \lambda$

$\therefore \quad V=(2-20) /-6=3$

Example-8

Solving the Pay-off matrix(2x2) Game

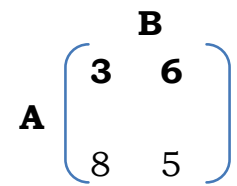

Sol:- Row Minima $\quad=(3,5)$ 
Column maxima $=(8,6)$

Min.of Column maxima $=6$ and

Max of Row minima $=5$

Min.ofCol.maxima $\neq$ Max of Row minima

\section{$\therefore \quad$ No Saddle Point}

Let $\mathrm{B}$ choose 3,6 with probability $\mathrm{x}, \quad(1-\mathrm{x})$ and choose 8,5 with probability $\mathrm{x}, \quad(1-\mathrm{x})$

$$
\begin{aligned}
& =3 x+6(1-x)=8 x+5(1-x) \\
& =3 x-6 x+6-8 x-5+5 x=0 \\
& =-6 x+1=0 \\
& x=1 / 6 ;(1-x)=5 / 6
\end{aligned}
$$

Strategy for $B=(1 / 6,5 / 6)$

Similarly for Strategy A:

Let A choose 3, 8 with probability y, (1-y) and choose 6,5 with probability y, (1-y)

$$
\begin{aligned}
& =3 y+8(1-y)=6 y+5(1-y) \\
& =3 y-8 y+8-6 y-5+5 y=0 \\
& =-6 y+3=0 \\
& y=1 / 2 ;(1-x)=1 / 2
\end{aligned}
$$

- Step-2: Let a new matrix R, from A by deleting its successive rows from the preceding ones, continuous as step- 1 .

$\mathrm{R}$ : (n-1) x n matrix.

- Step-3: Determine the magnitude of oddments corresponding to each row and each column of A. The oddment corresponding to $\mathrm{i}^{\text {throw }}$, $\mathrm{j}^{\text {th }}$ column of $A$ is defined as the determinant $\mid C_{i}$ | or $\left|R_{j}\right|$ by deleting the corresponding row/column as satisfied.

- Step-4: Consider the magnitude of oddments by deleting negative sign if available against their respective rows or columns.

- Step-5: Verify whether the sum of row oddments is equal to the sum of column oddments.

- Step-6: Compute the expected value of the game corresponding to the optimum mixed strategy determined above for the row player against to column player.

\section{Example-9 :}

\section{Solving the $3 \times 3$ game by the method of matrices:}

$$
A=\left(\begin{array}{rrr}
1 & -1 & -1 \\
-1 & -1 & 3 \\
-1 & 2 & -1
\end{array}\right)
$$

Strategy for $\mathrm{B}=(0.5,0.5)$

Value of the Game $=3(1 / 6)+6(5 / 6)$

$\therefore \quad \mathrm{V}=11 / 2$

\section{ARITHMETIC METHOD}

- Step-1: Let pay-off matrix $A=n x n$. Assume a new matrix $C$ whose first column is obtained from $A$ by subtracting $2^{\text {nd }}$ column from $1^{\text {st }}$; Second column is obtained by subtracting A's $3^{\text {rd }}$ column from $2^{\text {ndtill }}$ last column. Then Matrix ' $C$ ' becomes $\mathrm{nx}(\mathrm{n}-1)$. 


\begin{tabular}{|c|c|c|c|}
\hline 1 & -1 & -1 & 12 \\
\hline-1 & -1 & 6 & 6 \\
\hline-1 & 2 & -1 & 8 \\
\hline 12 & 8 & 6 & 26 \\
\hline
\end{tabular}

Strategy A : $\quad(12 / 26,6 / 26,8 / 26)$

Strategy B : $(12 / 26,8 / 26,6 / 26)$

Value of the game is :

[ $(12 / 26) \times(1)+(6 / 26) \times(-1)+(8 / 26) \times(-1)]$ $=(-2 / 26)$

\section{Example-10 :}

Compute the Pay of Optimum strategies :

$$
\text { A } \quad\left(\begin{array}{cc}
200^{B} & 80 \\
110 & 170
\end{array}\right)
$$

Sol:-

$$
\begin{aligned}
& \text { * } C=\left(\begin{array}{c}
120 \\
-60
\end{array}\right) ; \quad R=\left(\begin{array}{c}
90 \\
-90
\end{array}\right) \\
& \left|C_{1}\right|=-60 ;\left|C_{2}\right|=120 ; \\
& \left|R_{1}\right|=90 ;\left|R_{2}\right|=-90 ;
\end{aligned}
$$

Corresponding Augmented Matrix

$\left(\begin{array}{cc|r}200 & 80 & 60 \\ 110 & 170 & 120 \\ \hline 90 & 90 & 180\end{array}\right)$

Strategy A : $\quad(60 / 180,120 / 180)=(1 / 3,2 / 3)$

Strategy B : $(90 / 180,90 / 180=(1 / 2,1 / 2)$

Value of the game is :

$$
\begin{aligned}
& \text { [ }(1 / 3) X(200)+(2 / 3) X(110)] \\
& =140
\end{aligned}
$$

Let $2 \mathrm{x}$ n game with $\mathrm{A}=\mathrm{x}_{1}, \mathrm{x}_{2}$; where $\mathrm{x}_{2}=(1-\mathrm{x})$

$$
\mathrm{B}=\mathrm{y}_{1}, \mathrm{y}_{2}, \mathrm{y}_{3}, \ldots \mathrm{yn} .
$$

A's expected payoff varies linearly with $\mathrm{x}$,. According to the maximin criterion for mixed strategy, A should select that value of $\mathrm{x} 1$ which maximizes the minimum expected payoff This may be done by plotting the lines as a function of $\mathrm{x} 1$ in Graphical method.

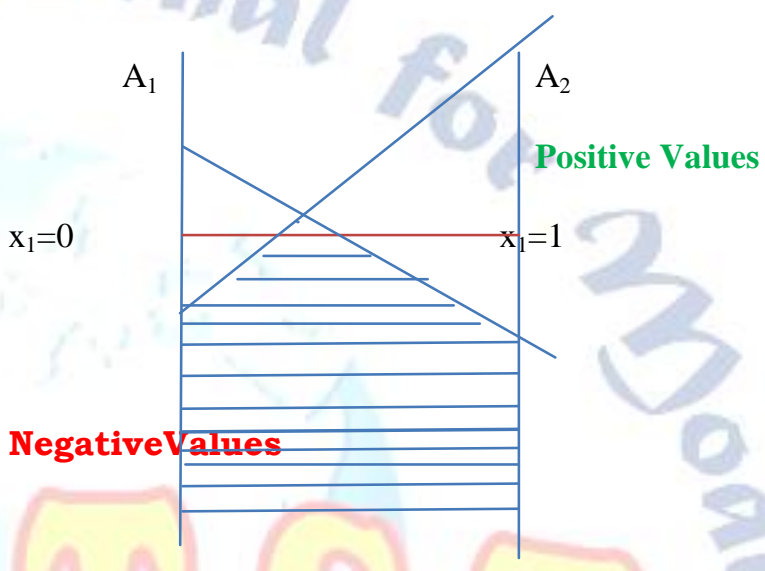

The lower boundary of these lines gives the minimum expected payoff to $\mathrm{A}$ as a function of $\mathrm{x}_{1}$. The highest point on this lower boundary gives the expected payoff to $\mathrm{A}$ and hence optimum value $\mathrm{x}_{1}=$ $\mathrm{x}_{1}{ }^{*}$. Similarlyfor $\mathrm{m} \times 2$ games we shall get minimax point which will be the lowest point on the upper boundary.

\section{Example-11 :}

L1
L2
L2
L3
L4 $\left(\begin{array}{lrrr}\mathbf{k}_{\mathbf{2}} & \mathbf{k}_{\mathbf{3}} & \mathbf{k}_{\mathbf{4}} \\ 6 & 4 & 6 & 4 \\ 11 & 2 & 13 & 7 \\ 7 & 6 & 17 & 3 \\ & 6 & 12 & 2\end{array}\right.$

Sol:-

Column (C1) is dominated by Column(C2) Column (C3) is dominated by Column(C4)

Deleting C1,C3 :

$\mathrm{L}_{1}$
$\mathrm{~L}_{2}$
$\mathrm{~L}_{3}$
$\mathrm{~L}_{4}$$\quad\left(\begin{array}{rr}4 & \mathbf{k}_{\mathbf{4}} \\ 2 & 4 \\ 5 & 7 \\ 6 & 3 \\ 2\end{array}\right)$

Representing each of $\mathrm{L}, \mathrm{K}_{2}, \mathrm{~K}_{4}$ values as a strategy in Axis - 1,2 


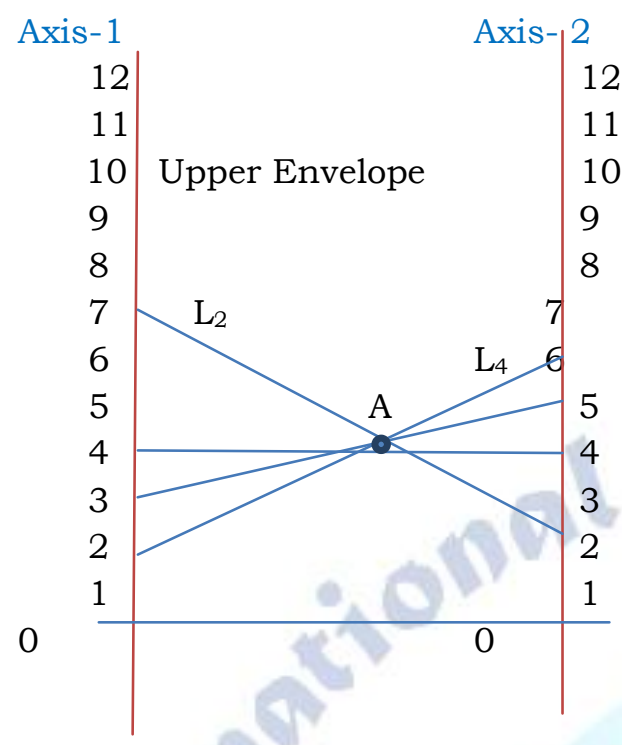

Lines passing through minimax is $\mathrm{L}_{2}, \mathrm{~L}_{4}$

Minimum of the upper envelop is as below:

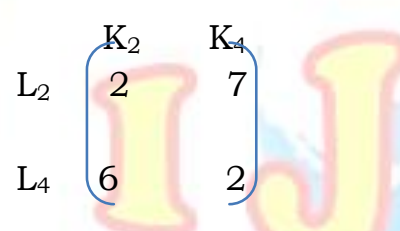

Using Expected Values determination approach method for $\mathrm{L}, \mathrm{K}$ :

$$
\begin{aligned}
& =2 \mathrm{y}+6(1-y)=7 y+2(1-y) \\
& =4-9 \mathrm{y}=0 \\
& \mathrm{~K}_{2}=\mathrm{y}=4 / 9 ;(1-\mathrm{y})=5 / 9=\mathrm{K}_{4} \\
& \mathrm{~S}_{\mathrm{L}}=\left(\begin{array}{llll}
\mathbf{k}_{1} & \mathbf{k}_{2} & \mathbf{k}_{3} & \mathbf{k}_{4} \\
0 & 4 / 9 & 0 & 5 / 9
\end{array}\right)
\end{aligned}
$$

Value of Game(V) : 2(4/9) + 6+(5/9)

$$
=39 / 9
$$

Similarly for $\mathrm{S}_{\mathrm{k}}$ :

$$
\mathrm{S}_{\mathrm{K}}=\left(\begin{array}{cccc}
\mathbf{k}_{\mathbf{1}} & \mathbf{k}_{\mathbf{2}} & \mathbf{k}_{\mathbf{3}} & \mathbf{k}_{\mathbf{4}} \\
0 & 5 / 9 & 0 & 4 / 9
\end{array}\right)
$$

\section{Conclusion}

It provided the Approach method of Solving the problems without saddle points. Explained the Concept of Linear Programming Method which is merged in Game Theory for easy understanding of given Problem. The pure strategy is a decision rule always to select a particulars course of action. In any payoff matrix we mention minimum of maximum by minimax and maximum of minimum by maximin. Saddle point is the point where the maximum of row minima coincides with the minimum of the column maxima then the payoff at the saddle point is called the value of the game denoted by ' $v$ ' in general.

In real life situation in general there are more than two competitors and hence balancing of gain and loss is also no always possible. Such type of condition is known as non-zero-sum-games.

\section{ACKNOWLEDGMENT}

I am extremely grateful to Prof.V.Kannan Former Pro-Vice-Chancellor of University of Hyderabad, who unconditionally gave me his valuable time and guidance in Research Activities. I wish to show my gratitude to my Academic Guru Dr.G.Manohar Reddy Garuand Dr.N.GouthamRaoGaru Management of Swamy Vivekananda Educational Trust,Hyderabad for their motivational thoughts and Support in Academics \& Research activities.

\section{REFERENCES}

[1] Wagner, H.M. Principle of Operations Research, Prentice-Hall of India,New Delhi, 1975.

[2] Trueman R.E. Quantitative Methods for Decision Making in Business Half-Saunders, New York, 1981.

[3] Swarup K. and M.Mohan, Operations Research, Sultan Chand,Delhi, 1986.

[4] Hahn.G.J and Meekaer, W.Q(1991).Statistical Intervals: A guide for Practitioners, John Wilery\&,Sons, New York.

[5] Rao K.V., Management Science, McGraw-Hill Book Co., Singapore, 1986.

[6] Middleton,D.(1960): An Introduction to Statistical Communication Theory, McGraw-Hill, New York.

[7] Chary S.N., Theory and Problems in Production and Operations Management, Tata McGraw-Hill Publishing Co.Ltd New Delhi, 1997.

[8] Applications of Queuing Theory in Quantitative Business Analysis: IJREAM - UGC Approved Journal,Vol-06,Issue-03,June-2020, Dr.DaruriVenugopal.

[9] Wylie,C.R.,Jr(1951): Advanced Engineering Mathematics, McGraw-Hill,New York.

[10] Dubes, R.C.(1968): The Theory of Applied Probability, Prentichall,Englewood Cliffs, New Jersey.

[11] Introduction to Modern Probability Theory: B.R. Bhat: Wiley Eastern.

[12] Introduction to probability and Mathematical Statics: V.K.Rohatagi:Wiley Eastern.

[13] Applications of Multivariate and Bivariate Analysis in Science and Engineering: Scopus Journal,Dr.DaruriVenugopal, (ISSN:2394-5125)Vol.7,Issue.15,2020. 